\title{
Effect of vitamin D3 on hyperplasia of mammary glands in experimental rats
}

\author{
Danfei Song ${ }^{1 \#}$, Xuejuan $\mathrm{Shi}^{2 \#}$, Changtian $\mathrm{Li}^{3}$, Xiaolin $\mathrm{Cao}^{1}$, Yuanyuan $\mathrm{Lu}^{1}$, Junlai Li ${ }^{1}$ \\ ${ }^{1}$ Department of Ultrasound, The Second Medical Center, Chinese PLA General Hospital, Beijing, China; ${ }^{2}$ Outpatient Department of Fengbei \\ Bridge, Southern Medical District of Chinese PLA General Hospital, Beijing, China; ${ }^{3}$ Faculty of Hepatopancreatobiliary Surgery, First Medical \\ Center of Chinese PLA General Hospital, Beijing, China \\ Contributions: (I) Conception and design: D Song, X Shi; (II) Administrative support: J Li, X Cao; (III) Provision of study materials or patients: D \\ Song, J Li; (IV) Collection and assembly of data: D Song, X Shi; (V) Data analysis and interpretation: Y Lu, C Li; (VI) Manuscript writing: All \\ authors; (VII) Final approval of manuscript: All authors. \\ \#These authors contributed equally to this work. \\ Correspondence to: Junlai Li. Department of Ultrasound, The Second Medical Center, Chinese PLA General Hospital, Haidian District, Fuxing Road, \\ Beijing 100853, China. Email: 52598983@qq.com.
}

Background 1,25(OH)2D3/vitamin D3 receptor (VD3/VDR) signaling pathway can inhibit the occurrence of breast cancer in many ways. We used vitamin D3 to interfere with Hyperplasia of mammary glands (HMG) model rats, and to explore the intervention effect of vitamin D3 on HMG.

Methods: We divided 42 female rats into six groups randomly: blank control group, hyperplasia model group, negative control group, and vitamin D3 (VD3) groups of low-dose (LVD, $5 \mu \mathrm{g} / \mathrm{kg}$ ), medium-dose (MVD, $10 \mu \mathrm{g} / \mathrm{kg}$ ), and high-dose (HVD, $20 \mu \mathrm{g} / \mathrm{kg}$ ). We established HMG model in all groups except for the blank control group, then different dose of VD3 was intraperitoneal injected for VD3 groups and normal saline (NS) was given to the negative control group. After the experiment, the body weights, heights and diameters of nipples, and the thickness of the mammary gland of rats were measured. The serum content of sex hormone and VD3 were detected by enzyme-linked immunosorbent assay (ELISA). The tissues of mammary glands were analyzed by hematoxylin and eosin (HE) stain, and the expression of estrogen receptor $\alpha(\mathrm{ER} \alpha)$, progesterone receptor (PR), and VDR were detected by immunohistochemical (IHC) stain. Similarly, the total protein expression of ER $\alpha, P R$, and VDR were measured by western blot.

Results: Compared with the hyperplasia group, rats in the VD3 groups displayed a marked decrease of the thickness of the mammary glands and the height and diameter of the nipples. The serum estrogen (E2), testosterone (T), luteinizing hormone (LH), and VD3 was markedly decreased in all VD3 groups $(\mathrm{P}<0.05)$. The IHC results showed that ER $\alpha$ and PR was decreased in all three VD3 groups; however, VDR was increased. Western blot demonstrated that both ER $\alpha$ and PR were reduced in VD3 groups, while the VDR level was significantly enhanced. Overall, the findings suggested that VD3 could be used in HMG treatment. Conclusions: Supplementation of VD3 could markedly decrease the mammary gland thickness, nipple diameter, and nipple height of rats, accompanied by the decrease of serum E2, T, and LH. Intervention with VD3 can lead to decreased expression of ERa and PR, in conjunction with the increase of VDR.

Keywords: Hyperplasia of mammary glands (HMG); vitamin D3; estrogen; therapy

Submitted Nov 09, 2021. Accepted for publication Jan 04, 2022.

doi: $10.21037 /$ gs-21-851

View this article at: https://dx.doi.org/10.21037/gs-21-851 


\section{Introduction}

Hyperplasia of mammary glands (HMG) is the abnormal quantity and morphology of mammary gland structure caused by different degrees of hyperplasia and degeneration of parenchyma and stroma of mammary gland lobules, and is caused by secretion disorder of estrogen (E2) and progesterone (P) $(1,2)$. The changes and development process from normal breast tissue to breast cancer include the usual ductal hyperplasia (UDH), atypical ductal hyperplasia (ADH), ductal carcinoma in situ (DCIS), and infiltrating ductal carcinoma (IDC). The HMG in clinic mostly refers to the UDH and ADH of the breast. To date, a large number of studies have shown that HMG is closely related to the occurrence of breast cancer and had a history of HMG is an important risk factor for IDC (3-6).

In recent years, there have been increasing reports on the molecular mechanisms of vitamin $\mathrm{D}$ in reducing cancer risk and inhibiting tumor development. Studies have shown that vitamin D deficiency is significantly associated with the development of several types of cancer, including colorectal, breast, pancreatic, and lung, and increased vitamin D intake, which inhibits the body's carcinogenic response to breast tumors, can significantly reduce a woman's risk of developing breast cancer $(7,8)$. Vitamin D is a fat-soluble vitamin, and vitamin D3 (VD3) is the active form of vitamin $\mathrm{D}$. The binding of VD3 and its receptor VDR into the nucleus can exert a wider range of biological effects. Increasing numbers of studies have focused on the development of VD3 in vivo active form and vitamin $\mathrm{D}$ analogs as clinical drugs for tumor prevention and treatment (9-11), but the preventive and therapeutic effects of VD3 on female breast hyperplasia have not yet been reported. In this study, an HMG model was established in experimental female rats, and different doses of VD3 were administered to the rats during the period of mammary gland hyperplasia. By observing the changes of mammary gland appearance, estradiol (E2) and progesterone $(\mathrm{P})$ level, mammary glands histopathology and expression differences of estrogen receptor $\alpha(E R \alpha)$, progesterone receptor (PR), and vitamin D3 receptor (VDR) after intervention, the feasibility of alleviating or treating HMG with VD3 was explored. We present the following article in accordance with the ARRIVE reporting checklist (available at https://gs.amegroups.com/ article/view/10.21037/gs-21-851/rc).

\section{Methods}

\section{Preparation of rat HMG model}

We purchased 42 4-6 weeks old (weight 86-162 g) specificpathogen-free (SPF) female Sprague Dawley (SD) rats from Beijing Weitong Lihua Experimental Animal Technology Co., Ltd. (Beijing, China). SD rats were fed under SPF condition in experimental Animal Center of PLA General Hospital. After adaptive feeding for 1 week before the experiment, during the sexual maturity of rats (6-8 weeks old), they were randomly divided into six groups: blank control group (Blank, $\mathrm{n}=5$ ), hyperplasia model group (Hyper, $n=5$ ), negative control group (Negative, $n=5$ ), and VD3 group (VD3, n=27) (n=9 in low, medium, and high dose groups). Except for the blank control group, HMG modeling was established in the other five groups by way of intraperitoneal injection of E2 (Sigma-Aldrich, St. Louis, MO, USA) $0.5 \mathrm{mg} / \mathrm{kg}$ for 25 days, followed by injection of progesterone (Sigma-Aldrich, USA) $4 \mathrm{mg} / \mathrm{kg}$ for 5 days. From the 10th day of modeling, the Negative group was injected with the same volume of normal saline (NS) (Solarbio, Beijing, China) and at the same time, $5 \mu \mathrm{g} / \mathrm{kg}$ VD3 (Sigma, USA) was administered to the low vitamin D3 group (LVD), $10 \mu \mathrm{g} / \mathrm{kg}$ VD3 (Sigma) was given to the medium vitamin D3 group (MVD), and $20 \mu \mathrm{g} / \mathrm{kg}$ VD3 (Sigma) was administered to the high vitamin D3 group (HVD) for 30 days (12).

After the experiment, the weight of each rat, the diameter and height of the ipsilateral second pair of nipples, and the thickness of the ipsilateral second pair of mammary glands were measured.

The tissue of the ipsilateral second pair of mammary glands of each rat was divided into two parts. One part was fixed with $4 \%$ paraformaldehyde (Solarbio, China), and the $\mathrm{ER}, \mathrm{PR}$, and VDR levels were analyzed by hematoxylin and eosin (HE) staining and immunohistochemistry (IHC). The other part was preserved with liquid nitrogen (Tianshun, Beijing, China), and the protein expression levels of ER, $\mathrm{PR}$, and VDR were detected by western blot.

Serum was collected from each rat and the levels of sex hormone [follicle-stimulating hormone (FSH), luteinizing hormone (LH), E2, P, Testosterone (T), Prolactin (PRL)] and VD3 were detected by enzyme-linked immunosorbent assay (ELISA).

Experiments were performed under a project license (No. 2018-X14-11) granted by Ethics Board of the Chinese PLA 
General Hospital, in compliance with Chinese national guidelines for the care and use of animals. A protocol was prepared before the study.

\section{Measurement of mammary gland thickness in rats}

Aixplorer ultrasound imaging (Supersonic Imagine, Aix-enProvince, France) was used, the probe was SL15-4, and the condition was set for small parts.

We adjusted the depth of ultrasonic field to center the image as far as possible and adjusted the focus to the interest region. Thick coupling gel (DOVE, Beijing, China) was applied to the surface of the ipsilateral second pair of mammary glands of rats, the probe was placed above the nipple without pressure, and the angle and direction of the probe were adjusted so that the ultrasonic image of the mammary gland was located in the center of the ultrasound display screen. After freezing the screen, the thickness of all subcutaneous soft tissue behind the rat nipple was measured, repeated 3 times, and the mean value was taken.

\section{Statistical analysis}

All statistical analyses were completed using the software SPSS 17.0 (IBM Corp., Chicago, IL, USA). Each experiment was carried out 3 times, and the quantitative data was expressed as mean \pm standard deviation $(\bar{x} \pm s)$. The discontinuous measurement data between groups were compared by rank-sum test, the continuous measurement data between groups were calculated and analyzed by single factor variance, and the differences between groups were calculated by Student's $t$-test. The level of statistically significant difference was set at $\mathrm{P}<0.05$.

\section{Results}

\section{Effects of VD3 on nipple diameter, height, and mammary gland thickness in rats with HMG}

The results showed that after 30 days of estrogenprogesterone stimulation, HMG was significantly induced in rats, and the mammary gland thickness, nipple diameter, and nipple height increased significantly. After the intervention of VD3 for 30 days, the mammary gland thickness of the three VD3 groups was significantly reduced and close to the $1.85 \mathrm{~mm}$ of the blank control group, and the difference was statistically significant $(\mathrm{P}<0.001)$. The thickness in LVD group decreased to
$1.76 \mathrm{~mm}$, MVD group to $1.71 \mathrm{~mm}$, and HVD group to $1.86 \mathrm{~mm}$, but there was no significant difference among the three groups. The nipple diameter in LVD group decreased to $1.26 \mathrm{~mm}$, MVD group to $1.27 \mathrm{~mm}$, and HVD group to $1.32 \mathrm{~mm}$, which was significantly lower than that in Hyper group $(1.90 \mathrm{~mm})$, but slightly higher than that in blank control group $(1.06 \mathrm{~mm})$. After VD3 intervention, the nipple height in LVD group decreased to $1.46 \mathrm{~mm}, \mathrm{MVD}$ group to $1.37 \mathrm{~mm}$, and HVD group to $1.57 \mathrm{~mm}$, which was significantly lower than that in Hyper group $(2.47 \mathrm{~mm})$. Among them, the nipple height in LVD group and MVD group were close to the blank control group $(1.4 \mathrm{~mm})$, while the HVD group was slightly higher than the blank control group, but there was no significant difference among the three groups (Figure 1, Table 1).

\section{Effects of VD3 on serum sex hormone and VD3 levels in rats with $H M G$}

The serum E2 and $\mathrm{P}$ were detected by ELISA. The results showed that after 30 days of $\mathrm{E} 2$ and $\mathrm{P}$ combined modeling, the serum E2 increased significantly $(\mathrm{P}<0.05)$, and decreased significantly after the intervention of $\mathrm{VD} 3$, especially in the MVD group; however, there was no significant difference among the 3 VD3 groups. The level of $\mathrm{T}$ in the Hyper group was significantly higher than that in the blank control group, suggesting that the secretion of endogenous estrogen was insufficient, and there were no significant changes in $\mathrm{P}, \mathrm{LH}, \mathrm{FSH}$, and PRL in the Hyper group and blank control group. After the intervention of VD3, the levels of $\mathrm{T}$ and $\mathrm{LH}$ in the VD3 groups were significantly lower than those in the Hyper group $(\mathrm{P}<0.05)$, but there was no significant difference among the 3 VD3 groups. There was no significant difference in FSH, PRL, and $\mathrm{P}$ among groups. The content of serum VD3 in the Hyper group was significantly higher than that in the blank control group, but the serum VD3 in the 3 VD3 groups was lower than that in the Hyper group, which is different from that in theory, and its specific mechanism needs further discussion (Figure 2).

\section{Effects of VD3 on microstructure of mammary gland tissue in rats with $H M G$}

The microscopic morphology of each group was observed under microscope after HE staining. The results showed that there were more ducts in the visual field of the Hyper group, and the morphological characteristics of HMG 

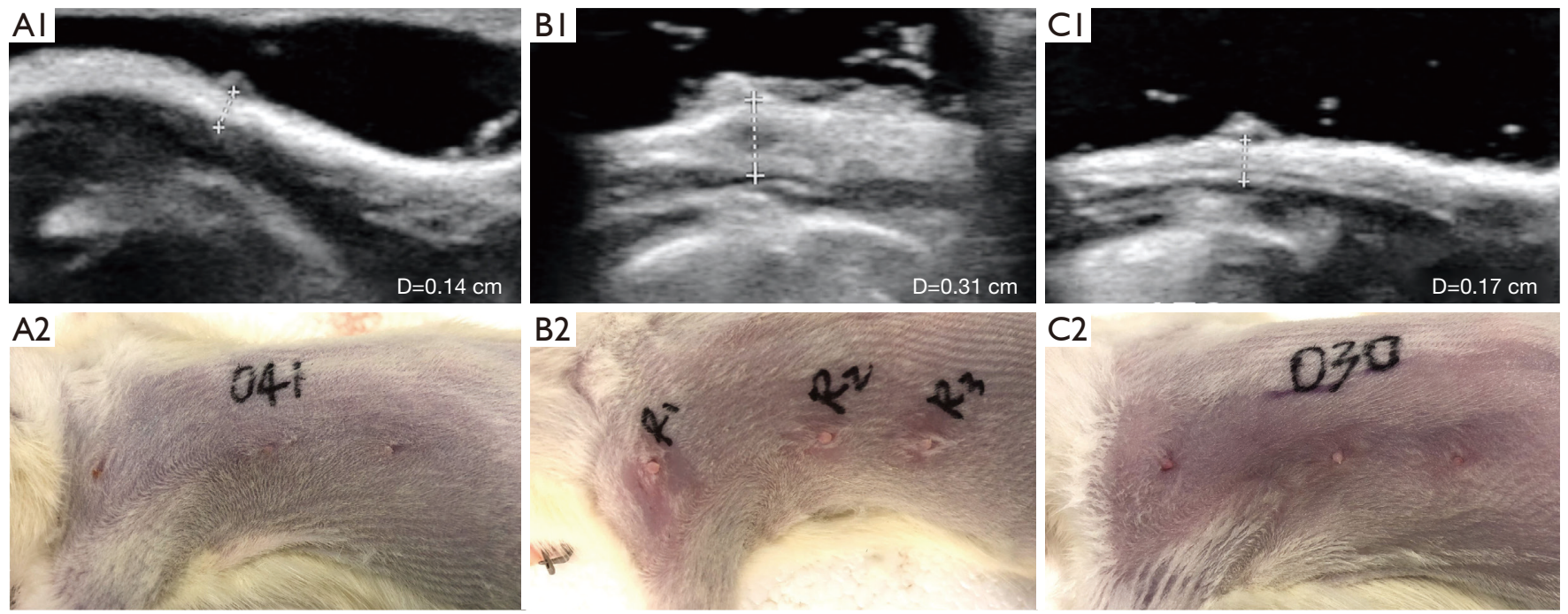

Figure 1 Comparison of mammary gland thickness and nipple size in blank control group (A1,A2), Hyper group (B1,B2), and VD3 group $(\mathrm{C} 1, \mathrm{C} 2)$. After VD3 intervention, the mammary gland thickness of the VD3 group (C1) was lower than that of the Hyper group (B1), which was close to that of the blank control group (A1), and the nipple size of the VD3 group (C2) was smaller than that of the Hyper group (B2). VD3, vitamin D3. R1, R2, R3: the first, second, third pair of nipples on the right.

Table 1 Effects of VD3 on mammary gland thickness, nipple diameter, and height in HMG rats

\begin{tabular}{lcccc}
\hline Group & Weight $(\mathrm{g})$ & Thickness $(\mathrm{mm})$ & Diameters $(\mathrm{mm})$ & Height $(\mathrm{mm})$ \\
\hline Blank & $239.60 \pm 15.31$ & $1.85 \pm 0.20$ & $1.06 \pm 0.17$ & $1.40 \pm 0.10$ \\
Hyper & $270.83 \pm 15.63$ & $2.24 \pm 0.40^{\star}$ & $1.90 \pm 0.17^{\star \star \star}$ & $2.47 \pm 0.42^{\star}$ \\
LVD & $249.14 \pm 19.77$ & $1.76 \pm 0.08^{\# \#}$ & $1.26 \pm 0.13^{\# \# \#}$ & $1.46 \pm 0.27^{\# \# \#}$ \\
MVD & $234.14 \pm 27.19$ & $1.71 \pm 0.16^{\# \#}$ & $1.27 \pm 0.20^{\# \# \#}$ & $1.37 \pm 0.24^{\# \#}$ \\
HVD & $246.83 \pm 48.05$ & $1.86 \pm 0.35^{\#}$ & $1.32 \pm 0.21^{\# \# \#}$ & $1.57 \pm 0.40^{\# \#}$ \\
\hline
\end{tabular}

${ }^{*} \mathrm{P}<0.05$, ${ }^{* *} \mathrm{P}<0.001$ vs. Blank group; ${ }^{\#} \mathrm{P}<0.05,{ }^{\# \#} \mathrm{P}<0.01,{ }^{\# \# \#} \mathrm{P}<0.001$ vs. Hyper group. HMG, hyperplasia of mammary glands; LVD, low vitamin D3; MVD, medium vitamin D3; HVD, high vitamin D3.

such as hyperplasia and disordered arrangement of ductal epithelial cells, enlarged lumen of ducts be seen under high power microscope, while in the VD3 groups, the lobules decreased significantly, the lumen of the lobular ducts shrank, and the epithelial cells arranged neatly. The microscopic morphology of the MVD and HVD groups was basically the same as that of the blank control group, suggesting that the HMG can be relieved obviously after the intervention of VD3 (Figure 3).

\section{Effects of VD 3 on IHC staining of related proteins in mammary gland tissue of rats with HMG}

The staining of VDR was analyzed by IHC staining.
Compared with the blank control group, the nucleus of some mammary duct epithelial cells in the Hyper group showed obvious staining, suggesting the high expression of VDR. After the intervention of VD3, the expression of VDR was significantly increased. VDR staining could be seen in the nucleus of mammary duct epithelial cells in the LVD, MVD, and HVD groups, especially in the HVD group, indicating that the intervention of VD3 effectively up-regulated the expression of VDR in mammary duct epithelial cells. It was suggested that VDR plays an important role in the remission of mammary gland hyperplasia.

The expression and distribution of ER $\alpha$ showed that only some of the mammary duct epithelial cells in the blank 
E2

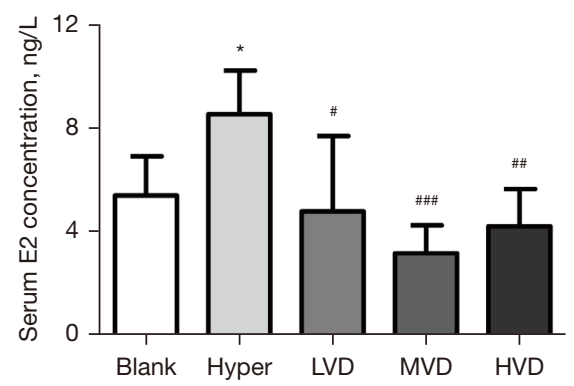

VD3

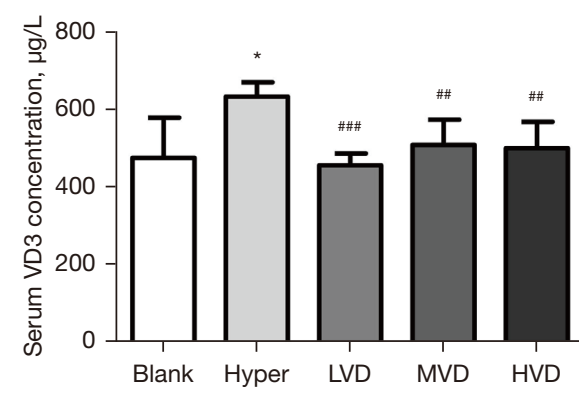

Figure 2 Detection of E2 and VD3 in rat serum by ELISA. After the intervention of VD3, the levels of serum E2 in LVD, MVD, and HVD groups were significantly lower than those in the Hyper group, and the levels of serum VD3 also decreased. Data are presented as mean \pm standard deviation, $\mathrm{n}=5$. *, $\mathrm{P}<0.05$ vs. Blank; " $\mathrm{P}<0.05$ vs. Hyper; ${ }^{\#}, \mathrm{P}<0.01$ vs. Hyper; ${ }^{\# \# \#, ~} \mathrm{P}<0.001$ vs. Hyper. E2, estradiol; VD3, vitamin D3; ELISA, enzyme-linked immunosorbent assay; LVD, low VD3; MVD, medium VD3; HVD, high VD3.
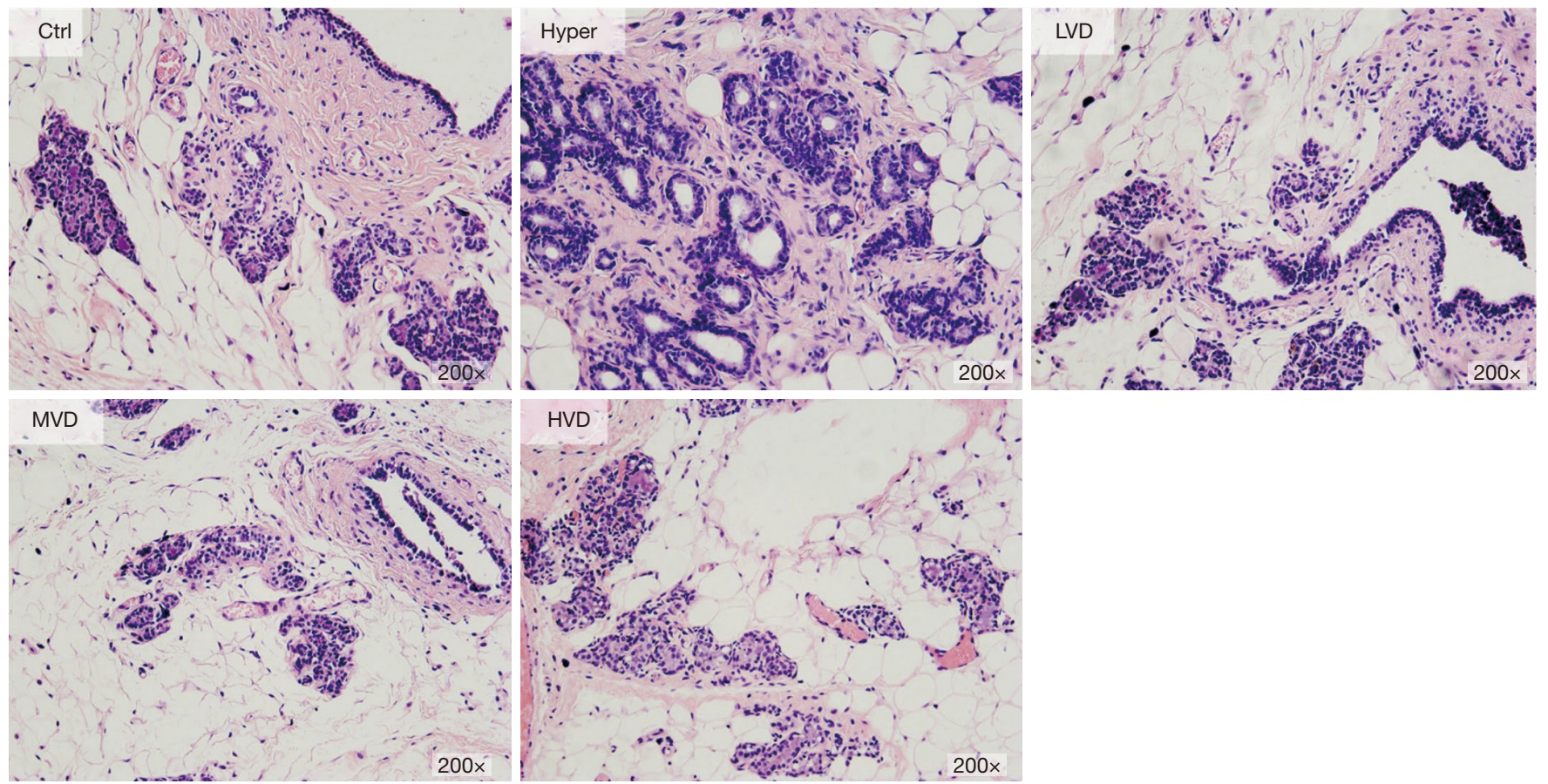

Figure 3 Results of HE staining of mammary glands tissue in each group (200x). After the intervention of VD3 in LVD, MVD, and HVD groups, the hyperplasia of mammary glands was relieved, which was consistent with that of the blank control group (Ctrl). HE, hematoxylin and eosin; LVD, low VD3; MVD, medium VD3; HVD, high VD3.

control group were slightly stained, and most of them were uniformly distributed in the nucleus, but in the Hyper group, ER $\alpha$ was highly expressed in the mammary gland tissue, most of the mammary duct epithelial cells were strongly stained, and mainly distributed in the nucleus, suggesting that $\mathrm{ER} \alpha$ entered the nucleus and played a role.
After the intervention of VD3, the staining of ER $\alpha$ was significantly reduced, and there was no staining in some cells in the LVD group and MVD group, suggesting that the expression of $\mathrm{ER} \alpha$ was inhibited after the intervention of VD3, thus alleviating the state of mammary gland hyperplasia (Figure 4). In addition, it was observed that 


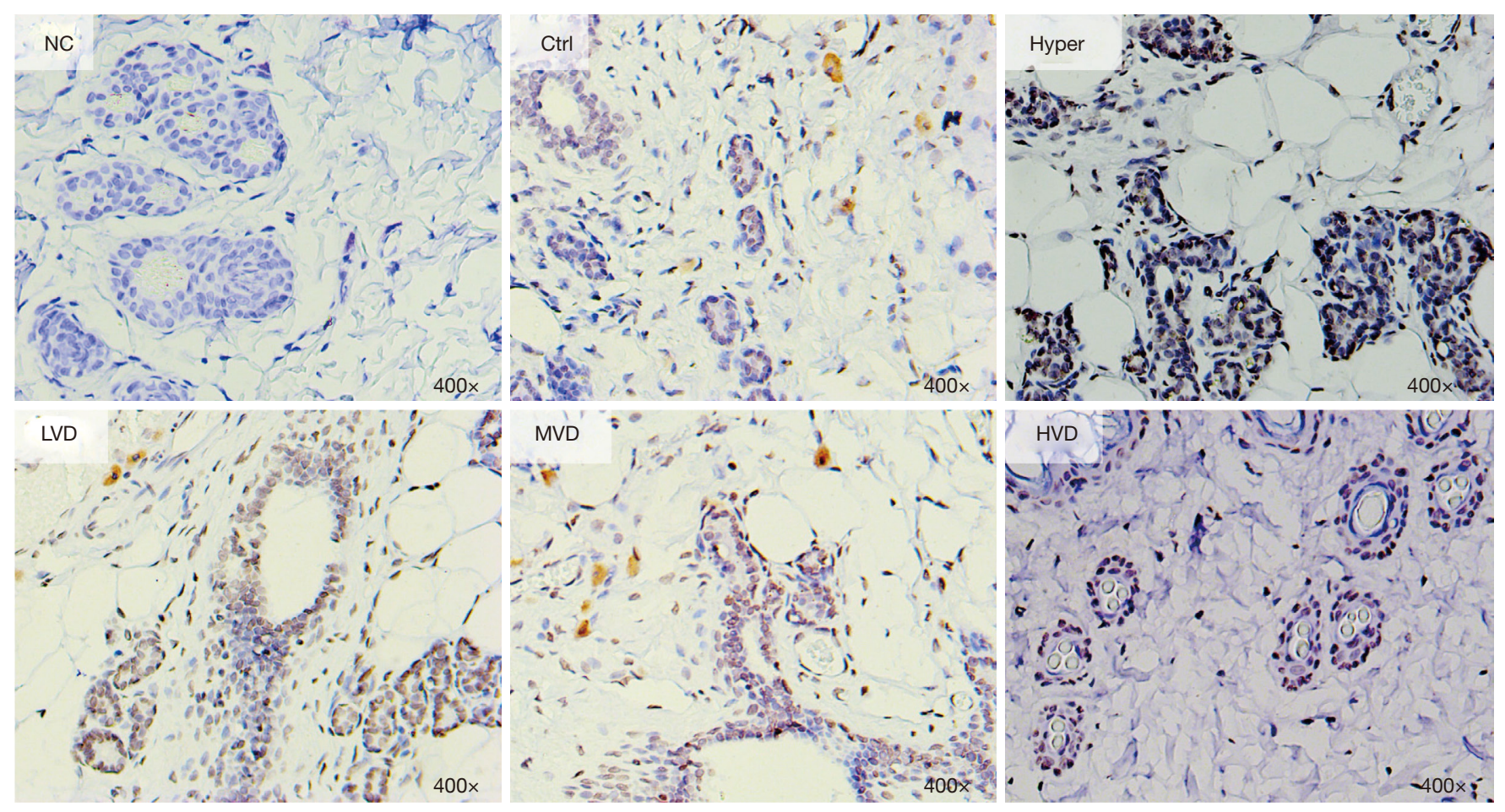

Figure 4 Detection of ER $\alpha$ expression in paraffin sections of mammary gland tissues by IHC (400x). After VD3 intervention, the staining of ER $\alpha$ in mammary gland ductal epithelial cells in LVD, MVD and HVD groups was significantly less than that in Hyper group. ER $\alpha$, estrogen receptor $\alpha$; IHC, immunohistochemistry; VD3, vitamin D3; LVD, low VD3; MVD, medium VD3; HVD, high VD3.

the staining of ER $\alpha$ in mammary duct epithelial cells was still dark in HVD group, which may be related to material selection or differences between groups, which requires further investigation.

To further study the mutual regulation mechanism of ER $\alpha$ and VD3 in mammary gland hyperplasia, we analyzed the IHC staining of PR in mammary gland tissue sections of rats in each group. The results showed that compared with the blank control group, most of the mammary duct epithelial cells in the Hyper group were strongly stained by PR staining, and the staining was mainly concentrated in the nucleus, which was consistent with the staining results of ER $\alpha$, indicating that the activation of ER $\alpha$ effectively recruits $P R$ and participates in the transmission of downstream signal pathways. After the intervention of VD3, the staining of PR in the nucleus decreased in varying degrees, and the staining in the LVD, MVD, and HVD groups showed a decreasing pattern, indicating that the activation of VDR caused by the increase of the dose of VD3 could effectively inhibit the expression of $\mathrm{PR}$ in the nucleus, which was consistent with the decrease of the expression of ER $\alpha$ in the nucleus after the intervention of VD3.

\section{Effects of VD3 on protein expression in mammary gland tissue of rats with HMG}

We detected the total protein in mammary gland tissue of rats in blank control group, Hyper group, and all VD3 groups (LVD, MVD, and HVD) by western blot, and analyzed the expression of ER $\alpha, \mathrm{PR}$, and VDR. The results showed that compared with the Hyper group, the expression of ER $\alpha$ and PR in the LVD, MVD, and HVD groups decreased significantly, of which the decrease of ER $\alpha$ was the most significant in the MVD group, and the decrease of PR expression in LVD group was the most significant. The protein expression of VDR in the mammary gland of rats in the LVD, MVD, and HVD groups was significantly higher than that in the Hyper group, especially in the MVD group, followed by the LVD group (Figure 5), indicating that VD3 can effectively up-regulate the expression of VDR in the mammary gland, and then inhibit the expression of ER $\alpha$ and its downstream PR protein, resulting in the relief of mammary gland hyperplasia. 


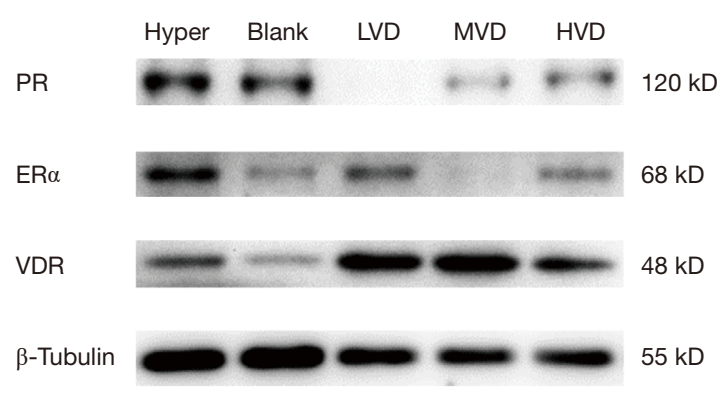

Figure 5 Detection of the expression of $\mathrm{ER} \alpha, \mathrm{PR}$, and VDR in rat mammary gland by western blot. The expression of ER $\alpha$ and PR in mammary gland tissue of the LVD, MVD, and HVD groups was significantly lower than that of Hyper group, while the expression of VDR was significantly higher than that of Hyper group. ER $\alpha$, estrogen receptor $\alpha$; PR, progesterone receptor; VDR, vitamin D3 receptor.

\section{Discussion}

In women, HMG is a frequently occurring disease. Studies have shown that HMG can account for $75 \%$ of all breast diseases. On account of its high incidence and the risk of breast cancer, HMG has become one of the important harmful factors to women's health $(13,14)$. Data show that the relative risk of breast cancer in UDH is 1.5-2 times higher than that in patients without proliferative breast disease, and the risk of $\mathrm{ADH}$ transforming into breast cancer is 4-5 times higher than that in UDH (4,15-17).

The pathogenesis of HMG is not fully understood, and more and more studies have proved that there is a close relationship between HMG and sex hormones. Current studies have shown that E2 can dilate and extend breast ducts, on the basis of which $\mathrm{P}$ can further promote the development of breast lobules, and PRL can promote the growth of mammary duct epithelial cells. the three hormones maintain the physiological hyperplasia or decline of the mammary gland during puberty and perinatal period. However, due to various internal and external factors leading to the imbalance of sex hormone levels in the body, especially the absolute or relative increase of E2, the mammary tissue cannot be changed from hyperplasia to restoration or incomplete restoration, which eventually leads to HMG $(18,19)$. At present, in vitro breast models are mainly prepared by using E2 and P. According to literature reports and previous studies, the rat model of HMG was established by intraperitoneal injection of estrogen $0.5 \mathrm{mg} / \mathrm{kg}$ for 25 days and progesterone $4 \mathrm{mg} / \mathrm{kg}$ for 5 days. In the selection of animals, female rats are often the first choice for the preparation of HMG models because of their strong reproductive ability, simple operation, and the changes of mammary tissue after the preparation of the model are similar to those of human HMG $(20,21)$. After 30 days of combined use of estrogen and progesterone, we found that the diameter of the nipple, the height of the nipple, and the thickness of the mammary gland were significantly increased, and the appearance changes were consistent with HMG. The levels of E2, VD3 and testosterone in serum of rats were significantly increased. HE staining showed that the volume of mammary lobules increased, the epithelial cells thickened and were arranged disorderly, and the lobular ducts dilated obviously in the Hyper group, which suggested that the mammary gland hyperplasia was obvious. The protein western blot analysis in the mammary gland tissue showed that the expression of ER $\alpha$ and VDR in mammary gland tissue of rats in Hyper group was significantly increased, which indicated that mammary gland hyperplasia was obvious in rats and suggested that VDR played an important role in HMG.

VDR is the intracellular receptor for VD3, a steroid hormone receptor that is essential for normal mammary gland development (22). Recent studies have shown that VD3 can induce apoptosis, block cell cycle, and inhibit tumor cell proliferation through its receptor VDR in many ways (23-25). In wild type cells, low dose of VD3 could induce G0/G1 cycle arrest and apoptosis, while VDR knockout cells did not produce cell cycle arrest and apoptosis even under the action of high dose of VD3. Research shows that VDR plays a key role in mammary gland development as a steroid hormone receptor. Knockout of VDR in mice can lead to obvious overgrowth of mammary gland, showing accelerated growth of mammary duct and occurrence of branching morphology. The results of isolation of primary mammary gland cells showed that the deletion of VDR could make the cells more sensitive to the stimulation of exogenous estrogen and progesterone $(26,27)$. And IL-6 secreted by mammary duct cells can increase cell proliferation and decrease cell apoptosis through autocrine and paracrine effects, leading to mammary duct extension and collateral formation, which means that E2 and VDR play an important role in mammary gland development (28). In addition, in the mouse VDR knockout cell model, the cell growth was significantly inhibited and the expression of VD3 target gene was restored after exogenous introduction of stable human VDR expression vector (29), indicating that VDR signal transduction pathway plays an important role in mammary gland development. 
In order to study the role and mechanism of VDR in the occurrence and development of HMG. On the basis of rat HMG model, we intervened with VD3 for 30 days. The LVD group was injected with $5 \mu \mathrm{g} / \mathrm{kg}$ VD3, the MVD group was injected with $10 \mu \mathrm{g} / \mathrm{kg} \mathrm{VD} 3$, and the HVD group was injected with $20 \mu \mathrm{g} / \mathrm{kg}$ VD3. The results showed that after the intervention of VD3 for 30 days, the mammary gland thickness of the 3 VD3 groups was significantly reduced, the nipple diameter was significantly lower than that of the Hyper group, and the nipple height decreased significantly after the intervention of VD3, but there was no significant difference among the three VD3 groups, indicating that $5 \mu \mathrm{g} / \mathrm{kg}$ VD3 could effectively alleviate the mammary gland hyperplasia in rats. It further shows that the VD3/VDR signal pathway can play an inhibiting role in HMG. In addition, the detection of sex hormone in the serum of rats in each group showed that the serum E2, $\mathrm{T}$, and LH decreased significantly after the intervention of VD3, but there was no significant difference in FSH, $\mathrm{PRL}$, and $\mathrm{P}$ among the three groups, suggesting that the inhibitory effect of VD3 on mammary gland hyperplasia did not affect the secretion of serum FSH, PRL, and P. The detection of the content of VD3 in serum of rats showed that the content of VD3 in serum of rats after intervention with VD3 was significantly lower than that in the Hyper group, which was different from that in theory, and its specific mechanism requires further investigation and discussion.

In order to further study and analyze the specific mechanism of VD3 regulating HMG in rats, paraffin sections of mammary gland tissues of rats in each group were stained with IHC staining. The results showed that after the combined stimulation of estrogen and progesterone, the staining of $\mathrm{ER} \alpha, \mathrm{PR}$, and VDR in the mammary glands of rats was significantly enhanced. After the intervention of VD3, the expression of $\mathrm{ER} \alpha$ and PR was significantly inhibited, the HMG was significantly alleviated, while the staining of VDR was increased, which further indicates that VD3 can resist the stimulation of exogenous estrogen and progesterone by activating intracellular VDR and inhibiting HMG-inducing factors such as ER $\alpha$ and PR. ER $\alpha$ and PR respectively present the signal transduction of estrogen and progesterone in mammary tissue, and they can directly or indirectly combine with a variety of transcription factors to play the role of transcriptional regulation and many intracellular signal pathways. In the transmission of ER $\alpha$ signaling pathway in mammary epithelial cells, PR/PRL presents ER $\alpha$ signaling and plays a key role in downstream cell functions. It can activate the activities of JAK and STAT proteins, and then participate in the proliferation and differentiation of mammary cells to maintain normal physiological functions of the breast (30). Similarly, this function also plays a key role in the occurrence and development of breast diseases, especially that of breast cancer. We analyzed the expression of ER $\alpha$, $\mathrm{PR}$, and VDR by western blot. The results showed that the expression of ER $\alpha$ and PR decreased significantly after the intervention of $\mathrm{VD} 3$, while the protein expression of VDR increased significantly, indicating that the upregulation of VDR can inhibit the expression of ER $\alpha$ and its downstream PR protein. It weakens the proliferation and division of mammary duct epithelial cells, inhibits the promoting effect of estrogen and progesterone on mammary gland hyperplasia, and finally inhibits the HMG of rats.

To date, a number of studies have confirmed that the VD3/VDR signal pathway can be involved in breast development and breast cancer. Zinser et al. found in VDR knockout mice that VDR deficient mice had less resistance to the carcinogen dimethylbenzanthracene (DMBA) in vitro, and were more likely to be induced into breast cancer and a higher proportion of hormone independent mice than wild-type mice. In addition, VDR deficient mice had more significant tumorigenesis in epidermis and lymphoid tissues. It is suggested that the deletion of VDR increases the susceptibility of tumor in mice (7). Primary cells were isolated from breast cancer in wild type and VDR knockout mice, and the malignant degree of cells was further observed by VD3 stimulation. The results showed that wild-type primary cells could normally express VDR and showed strong response to VD3, cell cycle arrest and apoptosis were obvious, while cells in VDR knockout group had no response to exogenous VD3, indicating that VD3 was involved in the regulation of breast cancer cell proliferation and apoptosis through VDR (31). In an organ culture experiment, it was found that the addition of exogenous VD3 could inhibit the formation of breast tumor induced by carcinogens in mice, while high VD3 diet and VDR agonists showed resistance to chemical carcinogens in vivo and inhibited breast tumor formation (7).

So far, there is no definite treatment for HMG. At present, most of the treatment of HMG is to use drugs to inhibit the function of estrogen, but this treatment can only alleviate the symptoms of mammary gland hyperplasia, not really eradicate, and the tissue that has already proliferated 
is difficult to recover and many adverse reactions have been associated. However, surgical treatment often causes greater injury or even sacrifice of the breast and has a high recurrence rate, so it is not easy for patients to accept such an intervention (32). The treatment of traditional Chinese medicine (TCM) has a good clinical effect, but there are many kinds of TCM decoction and there are often modified and subtractive prescriptions, and its fixed decoction is less, which is not conducive to the screening of effective prescriptions, thus the therapeutic effect may vary widely $(33,34)$.

In addition to maintaining calcium and phosphorus metabolism and bone development in vivo, VD3 can play a wider range of biological effects after binding to the receptor VDR into the nucleus, including inhibiting the proliferation of many types of cells, inducing apoptosis and differentiation, and regulating the function of the immune system. Our research showed that VD3 can inhibit the signal transduction of ER $\alpha$ and PR by inducing the expression of VDR in rat mammary gland tissue, resulting in the inhibition of mammary gland tissue cell hyperplasia, thus alleviating the proliferative effect of estrogen and progesterone on mammary gland tissue, which provides a new idea and research target for the prevention and treatment of clinical breast proliferative lesions. Vitamin D is an essential fat-soluble vitamin for the human body. VD3 is the active form of vitamin D. Vitamin D is mainly obtained from the synthesis of skin epidermis and dermis and a small amount of vitamin D is absorbed by food. As a kind of necessary nutrients for human body, VD3 has less side effect, cheap and easy to obtain. Appropriate amount of vitamin D supplementation for adult women (400-600 IU/d) (35) may be a new method for the treatment of HMG.

\section{Conclusions}

It has been shown that VD3 can effectively induce the expression of VDR and inhibit the expression of ER $\alpha$ and PR in rat mammary gland tissue, and finally inhibit the proliferation of cells in rat mammary gland tissue and alleviate the promoting effect of estrogen and progesterone on mammary gland hyperplasia.

\section{Acknowledgments}

Funding: This study received funding from the General Program of National Natural Science Foundation of China (No. 81771835).

\section{Footnote}

Reporting Checklist: The authors have completed the ARRIVE reporting checklist. Available at https:// gs.amegroups.com/article/view/10.21037/gs-21-851/rc

Data Sharing Statement: Available at https://gs.amegroups. com/article/view/10.21037/gs-21-851/dss

Conflicts of Interest: All authors have completed the ICMJE uniform disclosure form (available at https://gs.amegroups. com/article/view/10.21037/gs-21-851/coif). All authors report funding from General Program of National Natural Science Foundation of China (No. 81771835). The authors have no other conflicts of interest to declare.

Ethical Statement: The authors are accountable for all aspects of the work in ensuring that questions related to the accuracy or integrity of any part of the work are appropriately investigated and resolved. Experiments were performed under a project license (No. 2018-X14-11) granted by Ethics Board of the Chinese PLA General Hospital, in compliance with Chinese national guidelines for the care and use of animals.

Open Access Statement: This is an Open Access article distributed in accordance with the Creative Commons Attribution-NonCommercial-NoDerivs 4.0 International License (CC BY-NC-ND 4.0), which permits the noncommercial replication and distribution of the article with the strict proviso that no changes or edits are made and the original work is properly cited (including links to both the formal publication through the relevant DOI and the license). See: https://creativecommons.org/licenses/by-nc-nd/4.0/.

\section{References}

1. Mansel RE, Webster DJT, Sweetland HM, et al. Benign Disorders and Diseases of the Breast. Bailliere Tindal 2009:1-4.

2. Stachs A, Stubert J, Reimer T, et al. Benign Breast Disease in Women. Dtsch Arztebl Int 2019;116:565-74.

3. Hartmann LC, Radisky DC, Frost MH, et al. Understanding the premalignant potential of atypical hyperplasia through its natural history: a longitudinal cohort study. Cancer Prev Res (Phila) 2014;7:211-7.

4. Schnitt SJ. Benign breast disease and breast cancer risk: morphology and beyond. Am J Surg Pathol 
2003;27:836-41.

5. Simpson PT, Reis-Filho JS, Gale T, et al. Molecular evolution of breast cancer. J Pathol 2005;205:248-54.

6. Costarelli L, Campagna D, Mauri M, et al. Intraductal proliferative lesions of the breast-terminology and biology matter: premalignant lesions or preinvasive cancer? Int J Surg Oncol 2012;2012:501904.

7. Zinser GM, Suckow M, Welsh J. Vitamin D receptor (VDR) ablation alters carcinogen-induced tumorigenesis in mammary gland, epidermis and lymphoid tissues. J Steroid Biochem Mol Biol 2005;97:153-64.

8. Shin MH, Holmes MD, Hankinson SE, et al. Intake of dairy products, calcium, and vitamin $\mathrm{d}$ and risk of breast cancer. J Natl Cancer Inst 2002;94:1301-11.

9. Hossain S, Beydoun MA, Beydoun HA, et al. Vitamin $\mathrm{D}$ and breast cancer: A systematic review and metaanalysis of observational studies. Clin Nutr ESPEN 2019;30:170-84.

10. Manson JE, Cook NR, Lee IM, et al. Vitamin D Supplements and Prevention of Cancer and Cardiovascular Disease. N Engl J Med 2019;380:33-44.

11. Chandler PD, Chen WY, Ajala ON, et al. Effect of Vitamin D3 Supplements on Development of Advanced Cancer: A Secondary Analysis of the VITAL Randomized Clinical Trial. JAMA Netw Open 2020;3:e2025850.

12. Liu PY, Chen X, Jiang ZQ, et al. Effect of early vitamin $\mathrm{D}$ supplementation on lung inflammatory factors in baby rat with asthma. Zhonghua Yu Fang Yi Xue Za Zhi 2011;45:645-9.

13. Dupont WD, Page DL. Risk factors for breast cancer in women with proliferative breast disease. $\mathrm{N}$ Engl J Med 1985;312:146-51.

14. Degnim AC, Dupont WD, Radisky DC, et al. Extent of atypical hyperplasia stratifies breast cancer risk in 2 independent cohorts of women. Cancer 2016;122:2971-8.

15. Bombonati A, Sgroi DC. The molecular pathology of breast cancer progression. J Pathol 2011;223:307-17.

16. Tavassoli FA, Norris HJ. A comparison of the results of long-term follow-up for atypical intraductal hyperplasia and intraductal hyperplasia of the breast. Cancer 1990;65:518-29.

17. Schnitt S, Ellis I, van de Vijver MJ, et al. Intraductal proliferative lesions: introduction and overview. In: Lakhani S, Ellis IO, Schnitt SJ, et al. editors. WHO Classification of Tumours of the Breast. Lyon: IARC Press, 2012:82-3.

18. Schairer C, Hill D, Sturgeon SR, et al. Serum concentrations of estrogens, sex hormone binding globulin, and androgens and risk of breast hyperplasia in postmenopausal women. Cancer Epidemiol Biomarkers Prev 2005;14:1660-5.

19. Santen RJ, Mansel R. Benign breast disorders. N Engl J Med 2005;353:275-85.

20. Miao M, Wen Y, Bai M, et al. Specifications for Preparation of Mammary Gland Hyperplasia Models (Draft). Chinese Journal of Experimental Traditional Medical Formulae 2017;23:17-22.

21. Lucas JN, Rudmann DG, Credille KM, et al. The rat mammary gland: morphologic changes as an indicator of systemic hormonal perturbations induced by xenobiotics. Toxicol Pathol 2007;35:199-207.

22. Evans RM. The steroid and thyroid hormone receptor superfamily. Science 1988;240:889-95.

23. Mohseni H, Amani R, Hosseini SA, et al. Genetic Variations in VDR could Modulate the Efficacy of Vitamin D3 Supplementation on Inflammatory Markers and Total Antioxidant Capacity among Breast Cancer Women: A Randomized Double Blind Controlled Trial. Asian Pac J Cancer Prev 2019;20:2065-72.

24. Kazemian E, Akbari ME, Moradi N, et al. Vitamin D Receptor Genetic Variation and Cancer Biomarkers among Breast Cancer Patients Supplemented with Vitamin D3: A Single-Arm Non-Randomized Before and After Trial. Nutrients 2019;11:1264.

25. Sánchez-Céspedes R, Fernández-Martínez MD, Raya A, et al. Vitamin D receptor expression in canine mammary gland and relationship with clinicopathological parameters and progesterone/oestrogen receptors. Vet Comp Oncol 2018;16:E185-93.

26. Sheng L, Callen DF, Turner AG. Vitamin D3 signaling and breast cancer: Insights from transgenic mouse models. J Steroid Biochem Mol Biol 2018;178:348-53.

27. Thanasitthichai S, Chaiwerawattana A, Prasitthipayong A. Association of Vitamin D Level with Clinicopathological Features in Breast Cancer. Asian Pac J Cancer Prev 2015;16:4881-3.

28. Johnson AL, Zinser GM, Waltz SE. Loss of vitamin $D$ receptor signaling from the mammary epithelium or adipose tissue alters pubertal glandular development. Am J Physiol Endocrinol Metab 2014;307:E674-E685.

29. Keith ME, LaPorta E, Welsh J. Stable expression of human VDR in murine VDR-null cells recapitulates vitamin D mediated anti-cancer signaling. Mol Carcinog 2014;53:286-99.

30. Leehy KA, Truong TH, Mauro LJ, et al. Progesterone receptors (PR) mediate STAT actions: PR and prolactin 
receptor signaling crosstalk in breast cancer models. J Steroid Biochem Mol Biol 2018;176:88-93.

31. Zinser GM, McEleney K, Welsh J. Characterization of mammary tumor cell lines from wild type and vitamin D3 receptor knockout mice. Mol Cell Endocrinol 2003;200:67-80.

32. Ma W, Jin Q, Wu Y. Expert consensus on diagnosis and treatment of breast hyperplasia. Chinese Journal of Practical Surgery 2016;36:759-62.

33. Ma D, Liu G, Zhang X, et al. Massage treatment of hyperplasia of mammary glands: A protocol for a

Cite this article as: Song D, Shi X, Li C, Cao X, Lu Y, Li J. Effect of vitamin D3 on hyperplasia of mammary glands in experimental rats. Gland Surg 2022;11(1):136-146. doi: 10.21037/ gs-21-851 systematic review and meta-analysis. Medicine (Baltimore) 2020;99:e23601.

34. Chen S, Wang Q, Miu N. Research progress on the treatment of mammary hyperplasia with TCM internal therapy. Modern Journal of Integrated Traditional Chinese and Western Medicine 2021;30:903-7.

35. Cheng YY. Introduction to the Dietary recommended intakes (2013) Revised Edition. Acta Nutrimenta Sinica 2014;36:313-7.

(English Language Editor: J. Jones) 